\title{
RACIONALIDADE URBANA E ESPAÇOS RURAIS: A EMPRESA AGRÍCOLA UN1ONE E A VILA ALMEIDA EM JUIZ DE FORA - MG \\ URBAN RATIONALITY AND RURAL AREAS: THE UN1ONE AGRICULTURAL COMPANY AND VILA ALMEIDA IN JUIZ DE FORA - MG
}

\author{
Rafael de Souza Guedes ${ }^{1}$ \\ ${ }^{1}$ Escola Nacional de Ciências Estatísticas (ENCE-IBGE), Rio de Janeiro, RJ, Brasil
}

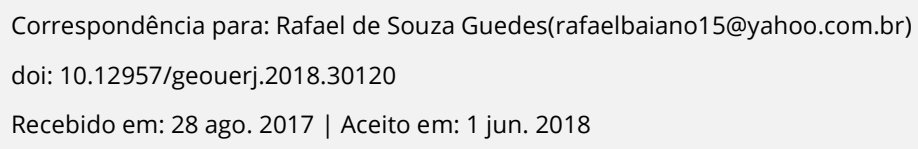

\section{RESUMO}

Espaços de campo e cidade se entrelaçam de muitas maneiras, assim como comportamentos rurais e urbanos. Neste artigo, analisamos as transformações sócio territoriais e as consequências da instalação de uma empresa agrícola no espaço rural da Vila Almeida, em Juiz de Fora/MG. As práticas e técnicas "urbanas" utilizadas no modo de operação da empresa e a configuração daquele espaço rural, que conta, no entanto, com infraestruturas e serviços tipicamente urbanos - como redes de esgoto e água e transporte público - suscitaram novos conflitos no cotidiano dos moradores, em sua maioria produtores agrícolas tradicionais. Atualmente eles vivenciam novas possibilidades de modificações em seu paradigma produtivo agrícola e em seu contexto de reprodução social. Há um estudo de caso realizado a partir de entrevistas semiestruturadas, o acompanhamento de uma reunião de moradores e os resultados colhidos. Buscou-se captar como se dá a presença de uma racionalidade urbana no espaço rural da Vila Almeida, sua dinâmica, e todas as condições e condicionantes que fazem parte desse processo. O resultado encontrado diz respeito a um fenômeno de integração entre cidade e campo que rechaça a ideia de dicotomia entre estes.

Palavras-chave: Empresa agrícola; Ruralidades; Urbano; Cidade.

\begin{abstract}
Field and city spaces intertwine in many ways as well as rural and urban behaviors. In this dissertation we analyze the social-territorial transformations and the consequences of the installation of an agricultural enterprise in the rural area of Vila Almeida, in Juiz de Fora / MG. The urban practices and techniques used in the company's operating mode and the spatial configuration of that rural area, which has typically urban infrastructures and services, though - like sewage and water networks and public transportation - sparked new conflicts in the daily lives of residents, mostly traditional farmers. They are currently experiencing new possibilities of changes in their agricultural production paradigm and in their context of social reproduction. There is a case study conducted via the application of semi-structured interviews, the follow-up of a meeting of residents and the results collected. We seek to capture how the presence of an urban rationality in the rural area of Vila Almeida is, its dynamics, and all the conditions and conditioning factors that are part of this process. The result found refers to a phenomenon of integration between city and countryside that rejects the idea of a dichotomy between them.
\end{abstract}

Keywords: Agricultural company; Ruralities; Urban; City

\section{INTRODUÇÃO}

Distintos contextos, rurais e/ou urbanos, são constituídos diariamente a partir do que os indivíduos produzem nesses espaços, e as transformações espaciais produzidas são objeto da abordagem nesse trabalho. O estudo visa analisar as transformações sócio territoriais na Vila Almeida, diante do 
fenômeno UN1ONE, com suas consequências sobre as formas de reprodução social dos indivíduos envolvidos e debater: o modo de operação da empresa, o modo de operação de outros produtores agrícolas da Vila e a presença de infraestruturas urbanas condicionadoras e condicionantes do espaço. Foi aplicada uma pesquisa qualitativa, em um estudo de caso com visitas a campo e realização de entrevistas semiestruturadas. $\mathrm{O}$ estudo de caso é uma estratégia de pesquisa utilizada para análise de um fenômeno em curso no âmbito natural (no contexto da vida real). O caso que abordaremos encontra-se na comunidade Vila Almeida, e o tipo de estudo é uma espécie de interação social, na qual o entrevistador pessoalmente participa da investigação. Foram aplicadas entrevistas semiestruturadas e captadas as respostas em gravações de áudio. As declarações consideradas mais relevantes e representativas foram transcritas e os participantes foram citados no trabalho com seus nomes fictícios.

Quanto a estrutura do trabalho, a priori é apresentada uma descrição do espaço da Vila Almeida ${ }^{1}$, local onde a empresa agrícola UN1ONE instalou-se, no município de Juiz de Fora/MG. Após a descrição inicial, há uma discussão sobre os variados critérios utilizados para a definição de conceitos referentes às temáticas rural, urbano, campo e cidade, seja por determinações administrativas ou legislações diversas, dados demográficos, dados econômicos e/ou questões territoriais. Há um apanhado do desenvolvimento histórico dos espaços de campo e cidade, desde os primórdios da divisão social do trabalho até a década de 1960 (período histórico de intensificação do processo de modernização no campo brasileiro e seus rebatimentos). Por fim, as transformações recentes ocorridas no contexto sócio espacial da Vila Almeida foram apresentadas seguidas pelas considerações finais desse trabalho.

\section{Descrição do local da pesquisa - a Vila Almeida e a empresa agrícola UN1ONE em Juiz de Fora}

1 Vila Almeida oficialmente um espaço rural de acordo com o Plano Diretor de Desenvolvimento Urbano municipal (PREFEITURA DE JUIZ DE FORA, 2000) 


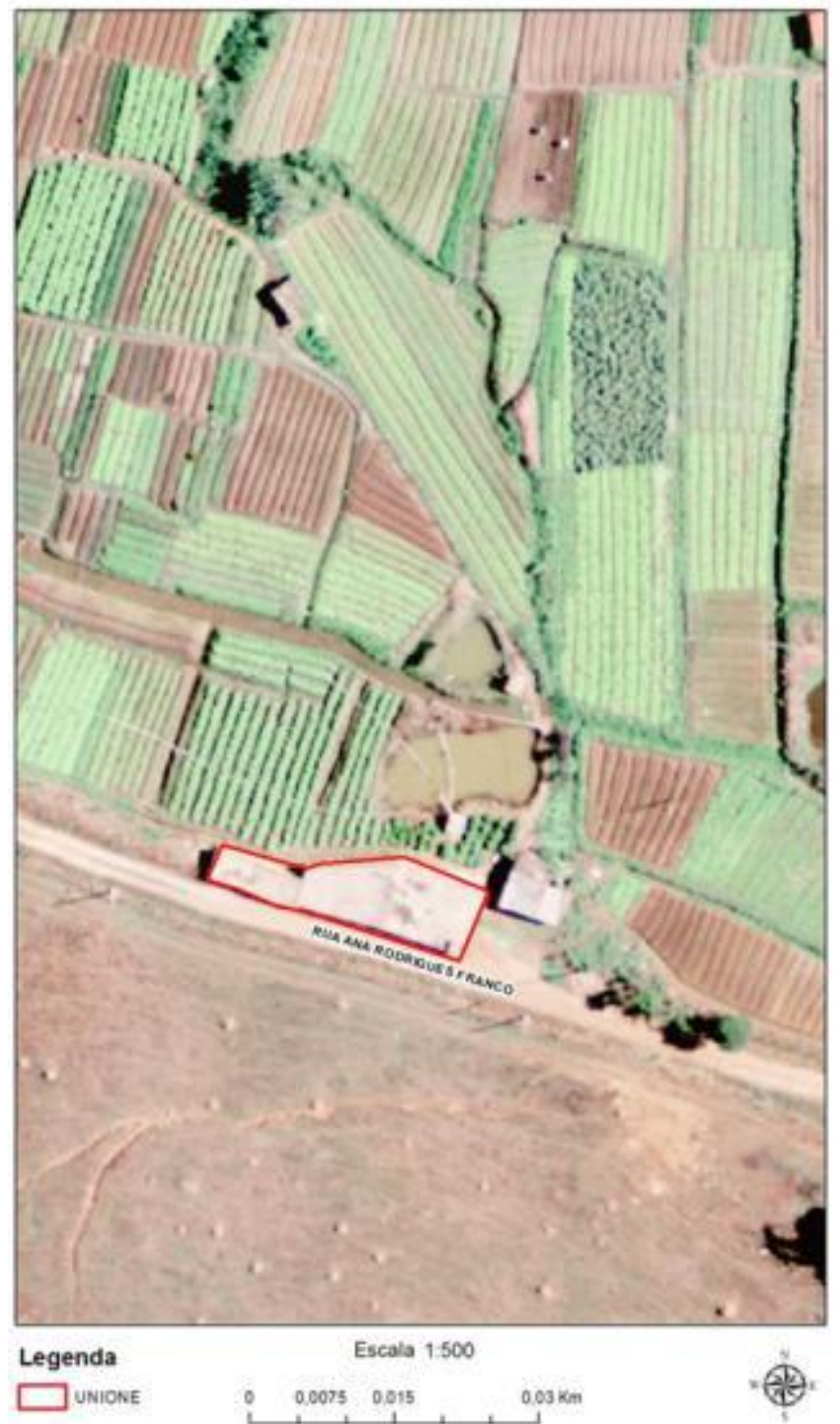

Figura 1. Imagem aérea da sede da empresa agrícola UN1ONE.

Fonte: Base Cartográfica Municipal de Juiz de Fora - Secretaria de Planejamento e Gestão (SEPLAG-JF).

Execução: Equipe Geoprocessamento da SEPLAG. Junho, 2016.

Fundada no ano de 2010, a UN1ONE (Figura 1) trabalha ano após ano para modernizar os processos produtivos e diminuir cada vez mais o percentual de perda de matéria-prima (hortaliças), porque a qualidade exigida pelos mercados centrais da cidade impõe o descarte do material que não possui a mais alta qualidade. É uma agroindústria que tem sede própria (escritório, garagem, salas diversas para trabalho com hortaliças, entre outras) em uma área construída de sessenta metros quadrados. Além disso, no local há também outros produtores agrícolas que trabalham por conta própria. 
Em seu cotidiano, os moradores da Vila Almeida estão imersos em uma dinâmica diária que mescla trabalhos agrícolas de plantações e cultivos de hortaliças - atividades tipicamente rurais - com infraestruturas e costumes citadinos, já que grande parte dos moradores do local convive com estruturas e serviços como rede de abastecimento de água, asfaltamento de ruas e iluminação pública (questões materiais). Além disso, lidam também com simbolismos (questões imateriais), como a influência cultural que o centro da cidade exerce sobre o cotidiano dos que ali residem; tais hábitos citadinos constituem as ditas urbanidades (RUA, 2007).

No ano 2000, de acordo com o Plano Diretor de Desenvolvimento Urbano, a Vila Almeida era considerada área rural não urbanizada, situação que se mantinha em 2016 conforme a Figura 2 (PREFEITURA DE JUIZ DE FORA, 2000).

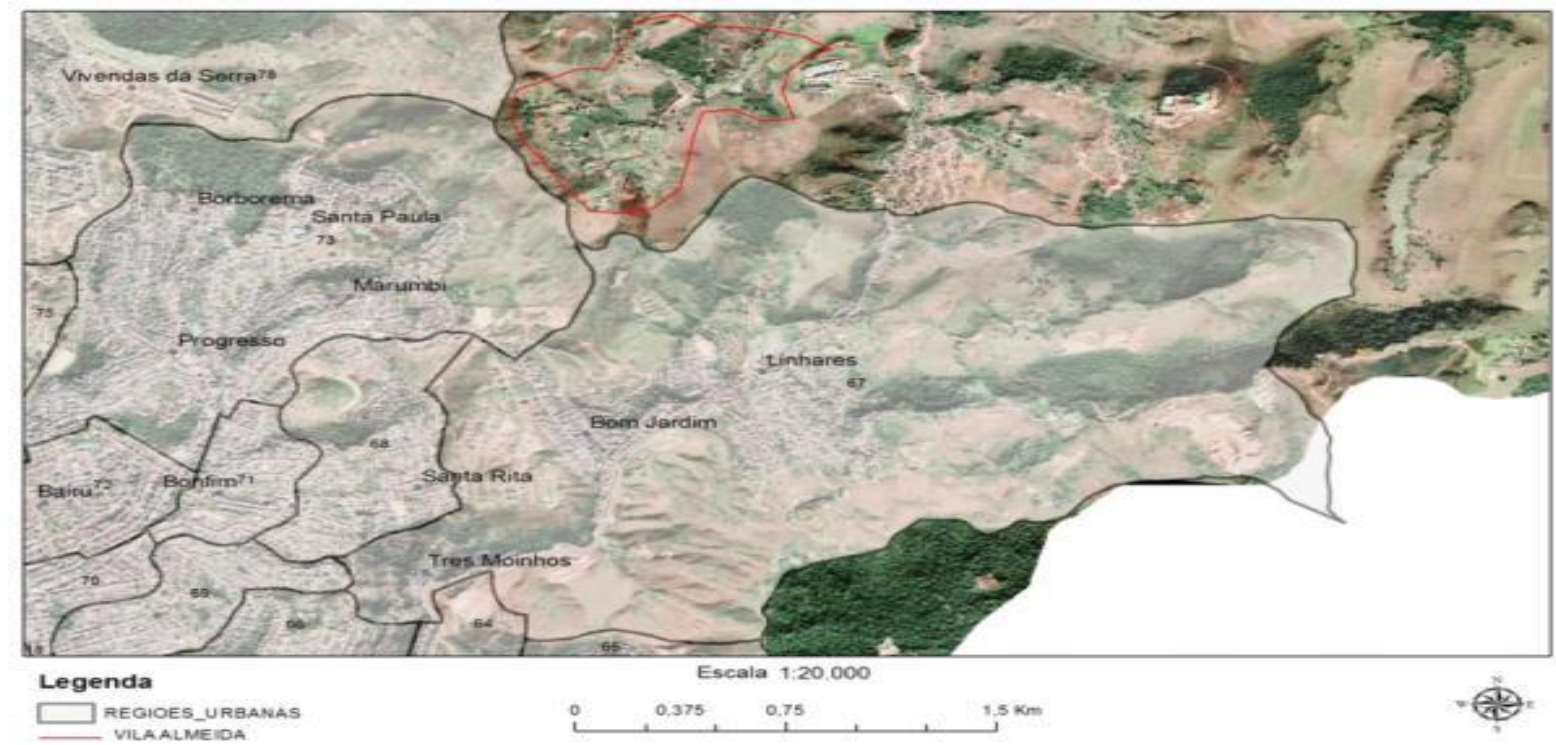

Figura 1. Imagem aérea da sede da empresa agrícola UN1ONE.

Fonte: Base Cartográfica Municipal de Juiz de Fora - Secretaria de Planejamento e Gestão (SEPLAG-JF). Execução: Equipe Geoprocessamento da SEPLAG. Junho, 2016.

\section{O que é o urbano? 0 que é o rural?}

A temática que engloba as discussões sobre os conceitos de rural e urbano é encarada a partir de diversas perspectivas ao redor do mundo e no Brasil, por exemplo, um núcleo importante envolto nestas análises e perspectivas é o CPDA, Programa de Pós-Graduação de Ciências Sociais em 
Desenvolvimento, Agricultura e Sociedade da Universidade Federal Rural do Rio de Janeiro (UFRRJ).

Dentre os principais conceitos sobre a temática, Endlich (2013) expõe que a definição destes termos pode ser trabalhada das seguintes formas: a primeira delas a partir da legislação oficial ou limites administrativos, que são divergentes em cada país, pois dependem de sua legislação nacional e baseiam-se fundamentalmente em questões territoriais. O segundo tipo de análise remete a uma questão demográfica, onde rural seria a dispersão populacional, e o urbano, a aglomeração, sendo que, por esse viés isolado, podem ser geradas complicações do tipo que a medida quantitativa em números absolutos não considera questões sociais dos indivíduos em questão. Outra análise demográfica diz respeito ao número de habitantes por quilômetro quadrado, porque desmitificaria o entendimento de que esvaziamento populacional seja sinônimo de rural, com baixa densidade populacional. Há também um entendimento de urbano e rural com base na classificação ocupacional dos indivíduos e na natureza das atividades econômicas que exercem; nesse caso, o rural seria o espaço das atividades primárias, enquanto o urbano seria o espaço das atividades secundárias e terciárias. Itália e Peru são exemplos de países que se utilizam deste critério para definição dessas áreas. Em sentido contrário, Endlich (2013) discorre sobre o fato de que as atividades econômicas atualmente estejam bastante entrelaçadas, e utilizar-se de uma análise deste tipo encontra cada vez mais obstáculos, visto que há um debate sobre novas práticas rurais que, atualmente, têm maior vinculação ao meio urbano.

Diante de todos os métodos de análise expostos, Endlich (2013) levanta a seguinte questão: seja qual for o critério utilizado, o que não se pode nunca deixar de levar em conta é que rural e urbano "são dimensões sociais produzidas no decorrer da história." (ENDLICH, 2013, p. 19). Partindo do entendimento de urbano a partir das relações sociais, campo e cidade localizam-se sob o modo de vida urbano globalizante, enquanto as expressões dos indivíduos nestes espaços, as ditas ruralidades e urbanidades, historicamente determinam, a partir de seus pontos de intercâmbios (fluxo de pessoas, instituições sociais, etc.), as condições em que se desenvolvem os sistemas produtivos humanos, de produção material e de reprodução da sua vida cotidiana. Esse é o entendimento da temática rural/urbano, embasado também em Lefébvre, o qual pontua que o tema carece de uma compreensão 
para além de dados estatísticos onde o conceito urbano é entendido como um processo de "formação social" (SOBARZO, 2013), ou seja, o termo urbano (global) abrange em si próprio as atividades e costumes tipicamente rurais (ruralidades) e as práticas urbanas (urbanidades), dentro dessa formação societária. Portanto, o próprio termo rural/urbano pode ser inapropriado para compreender a análise daquele autor, sendo preferível apreender a relação cidade/campo.

Lefébvre (1978) entende que a diferença inicial entre cidade e campo surge a partir da divisão do trabalho, com a cidade sendo centro administrativo, e o campo, somente centro de produção de alimentos. Entretanto, desde a antiguidade, a capacidade de alguns indivíduos produzirem produtos necessários à sobrevivência da coletividade liberou outros sujeitos desta atividade e, num momento de desenvolvimento posterior a essa divisão, seria errado pensar que o campo sucumbe às cidades, ou que a urbanização engole as atividades agrícolas. É fato, sim, que, ainda pelo viés das relações de produção, o campo absorve novas tecnologias e conhecimentos científicos advindos da cidade, mas as ditas ruralidades também têm seu significado; determinam e racionalizam alguns processos no espaço urbano .

Lefébvre (1978) destaca que o processo histórico do fenômeno da industrialização causou transformações espaciais, o que fomentou alguns problemas, dentre os quais, em alguns casos, a sobreposição das cidades sobre terras rurais anteriormente recheadas de tradições camponesas. Segundo o autor, a industrialização impôs uma descontinuidade histórica do modelo social anterior, tendo em vista que as relações sociais, que dão fruto ao urbano, foram transformadas.

O geógrafo James Amorim Araújo (2012) em sua análise Sobre a cidade e o urbano em Henri Lefébvre, que trabalhou em cima de duas obras do filósofo francês, O direito a cidade (1969) e A revolução urbana (1970), traçou o quadro que expõe este rompimento histórico. No período temporal das cidades políticas na Grécia antiga, no tocante à cidade e ao campo, a primeira divisão social do trabalho teria sido a responsável pela distinção das duas áreas, com o meio rural comportando camponeses, artesãos e escravos, e as cidades, os "homens livres". Posteriormente as práticas comerciais, que naquele momento eram de responsabilidade dos forasteiros que perambulavam como 
nômades, foram ressignificadas a partir da nova forma ascendente dos mercados. 0 conceito morfológico arquitetônico das cidades gregas foi implodido, visto que a centralidade social, anteriormente concentrada na Ágora (praça pública), passou para os espaços dos mercados, onde se concentravam os artesãos, os bancos e o comércio em geral. As mudanças nas cidades ressoaram no campo; aquelas passaram convencionalmente a ser concebidas como o lugar das liberdades, do moderno, enquanto o meio rural ganhou estigma de lugar tenebroso, do atraso. Já os costumes próprios e tradicionais dos grupos sociais naquele momento ainda estavam preservados, porque 0 incipiente modelo de trocas não deturpava ou dominava a prática social, o que posteriormente seria afetado, com o surgimento das cidades industriais, pós-maturação e evolução das práticas comerciais que culminaram no processo de industrialização (ARAÚJO, 2012).

Segundo Sobarzo (2013), para chegar ao conceito de urbano, Lefébvre executou a definição primeiramente de três grandes eras históricas: a agrária, a industrial e a urbana. No período agrário, o valor de uso das cidades ou do campo sobrepunha-se ao valor de troca desses espaços. Na sociedade industrial, porém, há uma generalização do valor de troca, e os próprios espaços passam a ser tornar os fatores principais, enquanto produtos e mercadorias, o que destrói a cidade em seu valor de uso, pois “o campo (e o rural) vem sendo percebido, já há algum tempo, como mercadoria (terra-mercadoria), capaz de gerar, graças ao trabalho, outras mercadorias, além das rendas obtidas pela especulação. " (RUA, 2006, p. 83). Mas isso não é o fim da urbanização, e, sim, sua generalização, sua transformação, pois o urbano passa a referir-se à sociedade inteira a partir das relações sociais que lhe dão significado, uma vez que são elementos que o compõem, que compõem a vida social. Cidade e campo são, portanto, materializações de uma vida urbana, de um conceito de vida virtual que possui suas expressões práticas, as urbanidades e ruralidades. Finalmente, a sociedade urbana é definida como um processo em movimento, uma tendência.

A partir da década de 1960, dentre o processo de modernização de propriedades agrícolas, foram implantadas diretrizes de aumento da qualidade e produtividade (por exemplo, adubação química e mecanização), voltadas para intensificação da produção mercadológica. O atual rural brasileiro, uniformizado pelos padrões das relações capitalistas, é altamente interligado à indústria, aos serviços e 
inclusive ao setor financeiro, associado ao modelo e seu dinamismo comercial. A análise socioespacial de influências das cidades sobre o campo indica que esse rural não é somente perpassado por padrões urbanos graças à contiguidade territorial, já que, em espaços fora dos perímetros urbanos e municípios pequenos interioranos, distantes dos centros, esta influência também pode ser encontrada (LIMA, 2005). O que para alguns autores se constitui em influências capitalistas no campo, para outros, como Octávio Ianni (IANNI apud CARNEIRO, 1998, p. 53), o que está em curso é o processo de "urbanização do mundo".

Já com base na legislação brasileira atual sobre limites espaciais e limites territoriais onde começam e/ou terminam espaços rurais e urbanos, Silva (2011), aponta que:

\footnotetext{
No Brasil vários municípios adotam a classificação das zonas rural e urbana, independente da característica da paisagem e da configuração social que elas assumem. [...] São cidades e vilas, muitas delas com características rurais, classificadas, entretanto como espaço urbano por força da legislação. Trata-se do Decreto Lei 311, de 1938, instituído durante a vigência do Estado Novo. O IBGE define, desde 1991, três categorias de áreas urbanas: urbanizadas, nãourbanizadas e urbanas-isoladas. Quanto ao rural, as categorias são extensão urbana, povoado, núcleos e outros. (SILVA, 2011, p. 6).
}

Silva (2011) analisa também que, no final do século XX, o fenômeno da globalização supõe existir um possível encurtamento das distâncias entre regiões do mundo, com base numa rede integrada de circulação de mercadorias. As cidades, por sua vez, assumiram o papel de eixos desta rede, enquanto centros de acumulação, regulação financeira e produção. A refuncionalização das cidades e a nova organização do espaço urbano reverberaram na relação da cidade com o campo, dado que muitas teorias surgiram apontando o fim do rural e do agrário, enquanto tantas outras teses, em sentido contrário, vieram enfocar o aprofundamento das singularidades do espaço rural (SILVA, 2011).

A circulação de produtos capitalizados sob a égide social, segundo a qual a "vida cotidiana serve à implantação do mundo das mercadorias" (LEFÉBVRE, 1978, P.10), faz parte de um aporte mais amplo que prega algumas "verdades" como se fossem únicas, porém, são somente hegemônicas, e o processo globalizante perpetua alguns destes mitos falsos. Por exemplo, o mito de que o espaço rural é o lugar da pobreza, das carências sociais e da falta de serviços públicos, sob o discurso de que o urbano é o espaço da modernidade. Ainda que, no início do processo de industrialização, as grandes concentrações populacionais tenham aparecido como o corolário do desenvolvimento, negar a 
importância do rural é uma falácia, visto que a própria produção de alguns alimentos que abastecem as cidades é uma das singularidades desses espaços (ABRAMOVAY, 2000).

Apesar desta distinção conceitual e teórica dos espaços, na contemporaneidade alguns autores trabalham e avançam no sentido contrário à falsa dicotomia rural/urbano, por exemplo, ao trazerem para o debate uma perspectiva elencada principalmente sobre as novas atividades não-agrícolas que ganham cada vez mais espaço no meio rural. Neste contexto de transformações, setores da economia encontraram espaço aberto para desenvolvimento, como afirmou Silva (2011), tais como o turismo e o lazer, que, em muitos casos, implicaram novas formas ao campo, dando-lhe nova estrutura. Foram criados hotéis fazendas, trilhas ecológicas, experiências com lavouras orgânicas, dentre outros. Esta nova morfologia do espaço rural, impulsionada pela evolução da infraestrutura urbana que as cidades expandiram para recriação de diferentes lugares, transformou-se em novas possibilidades "de geração de emprego e renda, de inserção de um amplo segmento da população ligada ao folclore, ao artesanato, às tradições, à confecção e prestação de serviços especializados” (SILVA, 2011, p.10).

Portanto, o quadro acima descrito pode exemplificar uma vertente de extrapolação da concepção de rural enquanto somente produtor de alimentos para as cidades, o que por si só já constituiria um nexo entre a Vila Almeida e o restante de Juiz de Fora, todavia avançando ainda mais na temática sobre vínculos entre os espaços, uma vez que, em muitos casos, o território dito rural já é perpassado por urbanidades e, talvez, por uma nova formatação socioespacial. Os simbolismos constituintes da ordenação territorial, urbanidades e ruralidades, fazem parte de uma vertente analítica que versa sobre os "espaços-processos" (RUA, 2005), ou seja, espaços definidos a partir das relações sociais que ali se dão, sendo que estes são constituídos por dinâmicas próprias e entendê-las em sua essência (seus movimentos e contradições), explicando o porquê de suas configurações estruturais.

\section{As transformações e o desenvolvimento recente da área rural da Vila Almeida}

Uma análise social da área Vila Almeida foi realizada pela EMATER-MG em parceria com produtores rurais da Vila Almeida e, em 06 de Setembro de 2011, foi publicado o Programa de Desenvolvimento 
Sustentável da Comunidade de Vila Almeida. Na ocasião foi realizado um diagnóstico participativo e, em parceria com a Secretaria de Agropecuária e Abastecimento (SAA-JF) e toda a comunidade da Vila Almeida, foram captados dados a respeito da comunidade e organizados os temas de interesse de seus participantes. A agropecuária foi detectada como a principal atividade econômica, sendo a olericultura com o cultivo de folhosas (alface, cebolinha, almeirão, rúcula, dentre outras) a atividade predominante. A produção, naquele momento, rendia anualmente 819 toneladas, correspondentes a $22 \%$ da produção de horticulturas do município de Juiz de Fora. No ano de 2011, na Vila Almeida (localizada no cinturão verde do município), 45 produtores da agricultura familiar eram responsáveis diretos pelo desenvolvimento da cultura de hortaliças, enquanto 191 pessoas participavam indiretamente dos processos de produção, preparo e comercialização. Além da horticultura, também havia produção de banana, exploração de leite e floricultura, e a grande maioria dos produtos locais eram comercializados em feiras livres de Juiz de Fora, na Unidade de Processamento Mínimo de Hortaliças "UN1ONE”, em mercearias diversas e na CEASA-MG (EMATER, 2011).

A práxis contemporânea estruturante da sociabilidade de sujeitos viventes no contexto da Vila Almeida incita uma nova dinâmica socioespacial, perpassada por diretrizes citadinas, que trazem nitidez às recentes transformações em processo e que configuram territorialmente a Vila Almeida na atualidade. Este quadro espacial que comporta "múltiplas territorialidades explicitadas num rural cada vez mais complexo, composto por lugares de interações em que o interno e o externo estariam em permanente, embora assimétrica, negociação, formando territorialidades em devir.” (RUA, 2011, p. 6) nos impõe a necessidade de transcender aquela definição, também já superada por João Rua (2006), segundo a qual o rural é considerado tudo aquilo que não é urbano. São necessárias novas análises sobre este espaço rural "fortemente marcado pelo conteúdo de técnica e capital" (MARAFON, 2014, p.2), e que conta com uma constante "expansão das vias de comunicação, como estradas, telefonias e meios de transporte" (MARAFON, 2014, p. 2 e 3). 


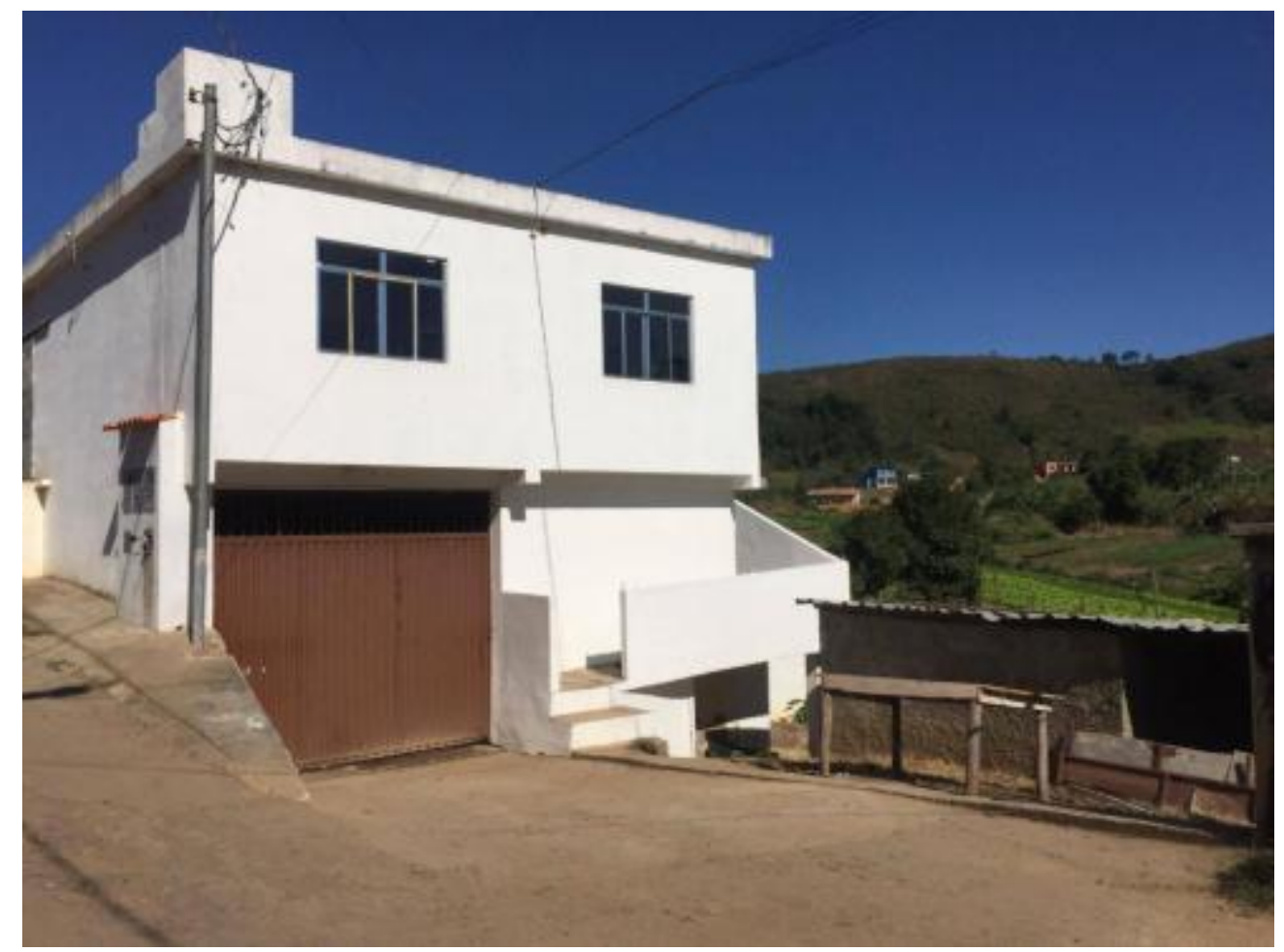

Figura 3. Sede da empresa agrícola UN1ONE, localizada na Vila Almeida em Juiz de Fora/MG 2016. Fonte: acervo pessoal do autor.

Um dos expoentes de urbanidade presentes na Vila Almeida, a empresa UN1ONE (figura 3) conserva em seu bojo institucional uma série de novas condicionantes ao cotidiano da Vila, trazendo um conflito de tradições produtivas agrícolas, entre produtores mais arcaicos e a empresa altamente urbana, o que suscita latentes contradições. Para muito além de questões sobre o sistema de produção, os rebatimentos do fenômeno UN10NE se espraiam pela cultura local, e provocam a mescla de hábitos e simbolismos rurais e urbanos. O que a priori e superficialmente denota um choque cultural, posteriormente desvelado em suas categorias mais simples de análise, clarifica a totalidade em seu movimento real (NETTO, 1997), uma vez que as condições de reprodução dos indivíduos, suas formas de apropriação daquele espaço e suas representações sociais são condicionadas pelo estágio de desenvolvimento das técnicas, infraestruturas e quesitos imateriais presentes na Vila.

A empresa agrícola UN1ONE desde sua fundação, e concomitantemente a todo o seu período em funcionamento, possui diretrizes tipicamente urbanas que perpassam os objetivos mercantis da empresa, a partir das parcerias com a Empresa de Assistência Técnica e Extensão Rural do Estado de 
Minas Gerais (EMATER-MG), com o Serviço Brasileiro de Apoio às Micro e Pequenas Empresas (SEBRAE), com a Universidade Federal de Viçosa - MG (UFV) e com a Empresa Brasileira de Pesquisa Agropecuária (EMBRAPA). Todo o arcabouço de conhecimento adquirido pela proprietária da UN10NE, Maria, embasou sua perspectiva mercadológica e a fez transcender modelos arcaicos de produção (figura 4) e optar por não produzir suas próprias verduras e nem sequer comprar hortaliças da própria Vila Almeida para revenda.

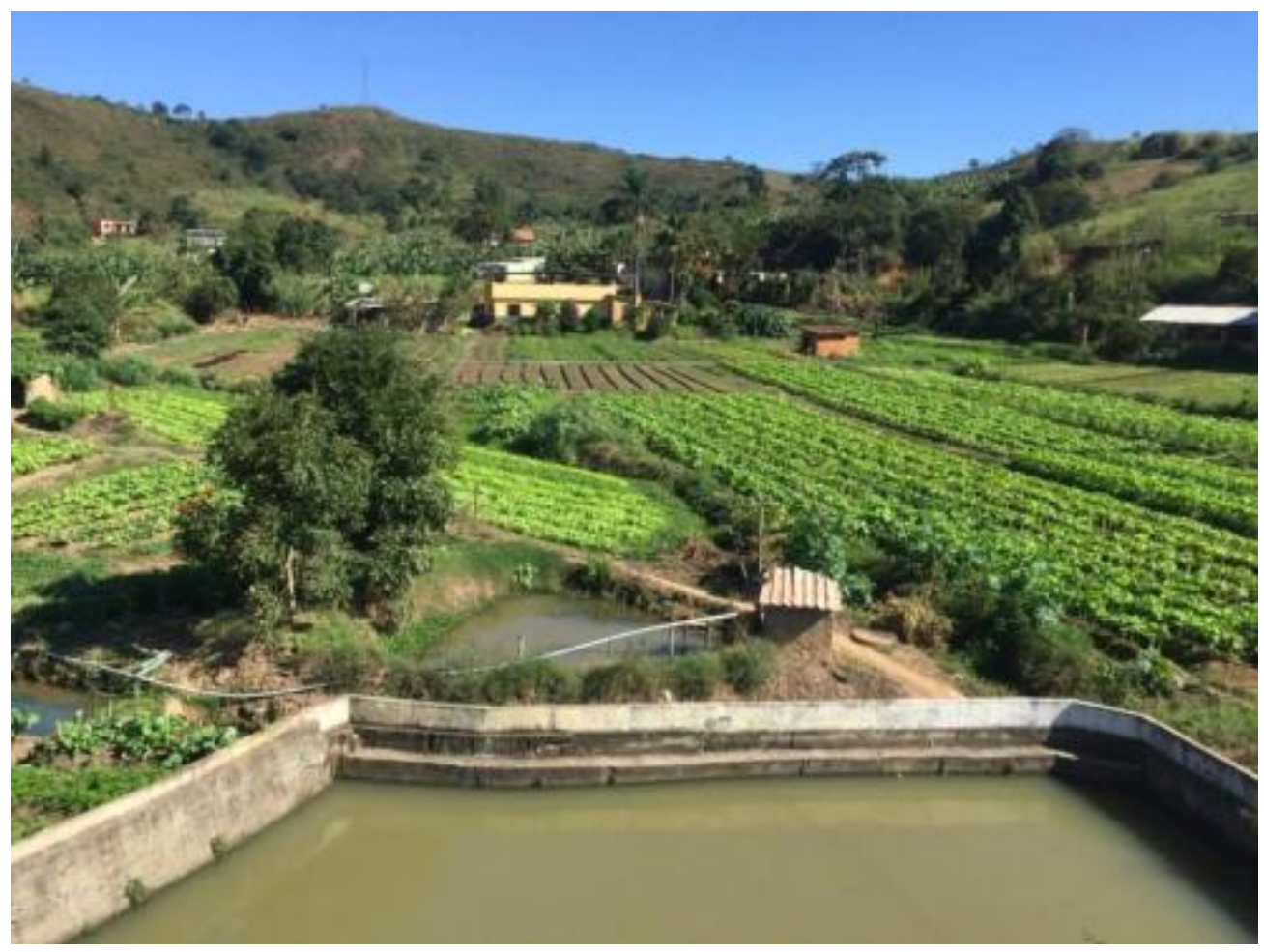

Figura 4. da Hortas da Vila Almeida sob moldes tradicionais, 2016.

Fonte: acervo pessoal do autor.

Os atuais fornecedores de matéria-prima para a UN1ONE possuem áreas de cultivo na cidade de Tabuleiro (MG) e cultivam hortaliças pelo método hidropônico. A instalação da UN1ONE na Vila contribui para solapar as bases do modelo de comunidade onde os laços de proximidade entre indivíduos são mais densos, presentes desde o momento embrionário da Vila Almeida, a partir da sobreposição de determinantes substancialmente industriais em relação a vetores de ruralidades tradicionais - ainda que não os elimine por completo - e, deste modo, a empresa agrícola "urbana" agrega valores a seu sistema racional e contribui para a superação das contradições. Consequentemente, através de um viés político-social, a UN1ONE constitui preponderância no 
mercado de hortaliças específico para hotéis, buffets, escolas, restaurantes e hospitais. Internamente, adotar a técnica hidropônica viabilizou o aumento dos lucros advindos da produção (dado a outra parte da renda obtida ser direcionada para investimentos em novas tecnologias na própria empresa), porque, dos antigos doze funcionários de carteira assinada que trabalhavam na empresa e faziam higienização das antigas hortaliças advindas das culturas tradicionais, somente dois ainda cumprem tal função e 0 fazem com maquinário adaptado (figura 5).

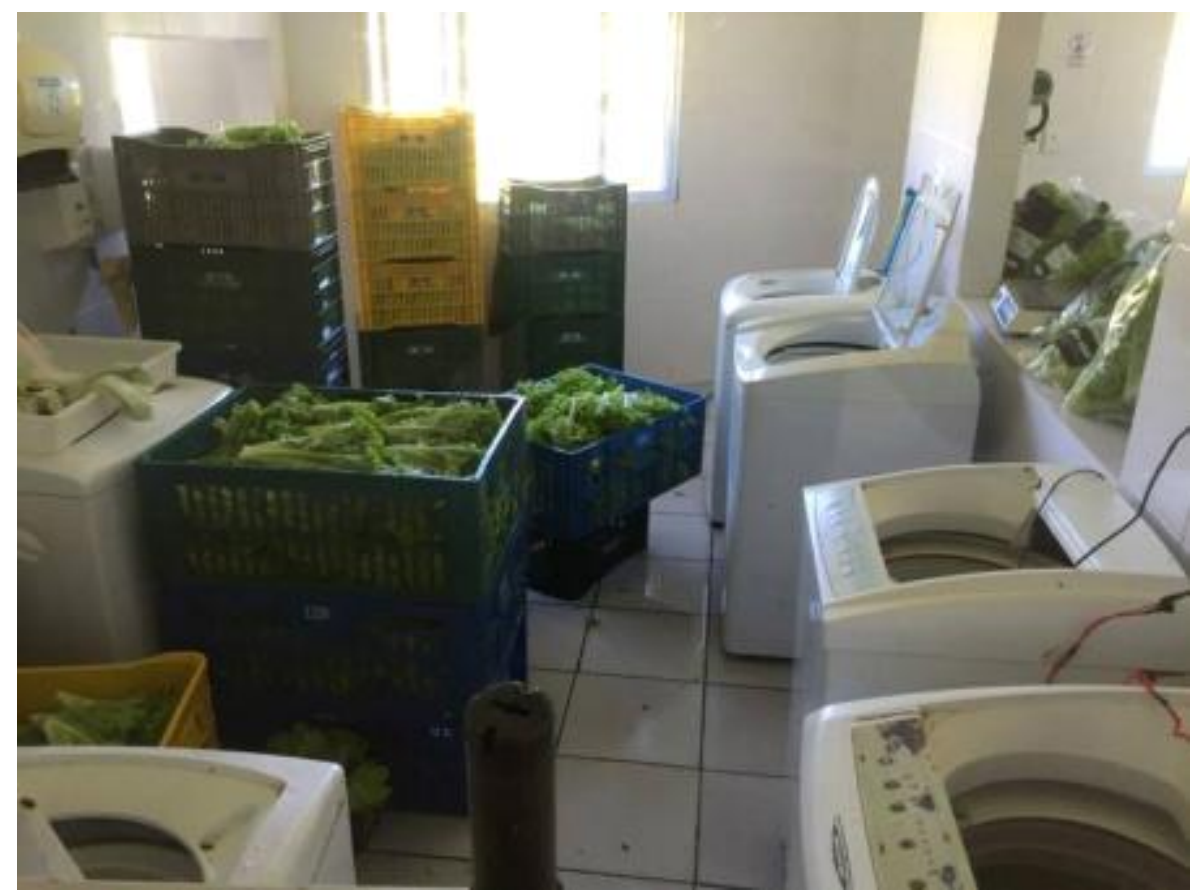

Figura 5. Salas de higienização, sanitização, mensuração e empacotamento de hortaliças. Fonte: acervo pessoal do autor.

A empresária Maria afirmou:

Hoje eu faço meu mercado. Eu preciso, sim, dos meus clientes, mas eu sei aonde é vantagem, quais são as verduras vantajosas para nós. Antes trabalhávamos com trinta e três produtos. Hoje com cinco (crespa, roxa, rúcula, agrião e às vezes couve), mas são essas cinco que vendem e que dão lucros. (MARIA, 2016).

Com base em Rua (2006), naquele espaço local da Vila, a tecnificação, a lógica e a racionalidade mercadológica latentes se dão de maneira muito densa em um território híbrido, contribuindo para determinar nova espacialidade local. A expansão da empresa UN1ONE fomenta novas territorialidades que interioriza naquele cotidiano uma reorganização do espaço pautada por diretrizes capitalistas e urbanas (RUA, 2011). 
Um dos moradores da Vila, Juvenal, é produtor rural e trabalha num sistema de agricultura familiar, cultivando, dentre outros produtos, alface, rúcula e almeirão. Ele chegou à Vila Almeida no ano de 1983 juntamente com um grupo formado por parentes, amigos e ex-vizinhos, que vieram de uma área conhecida por Almeida, pertencente ao município mineiro de Santa Rita do Ibitipoca. Almeida inclusive é o nome que inspirou ao batismo da região como Vila Almeida, em Juiz de Fora. Essa nomenclatura surgiu após a criação da associação de moradores do local, em 1985. A respeito do sistema produtivo UN1ONE, Juvenal discorre:

Eu acho que o estilo de produção da UN1ONE não vai ser adaptado na nossa horta, não. Eu vendo para mercado pequeno, o nosso é agricultura familiar. O dela é mais uma empresa mesmo. Eu fazia a feira, aí sempre aparece um, né: "Você não vende no atacado não?" Aí começou um, aparecia o outro, aparecia o outro, aí eu tive que parar com a feira. Escolhi mais a entrega em mercado, porque a gente já rala a semana inteira, aí quando for no domingo você fica lá até as 14 horas, sendo que começou trabalhar na horta às 4 da manhã. Aí o domingo acaba. Chega segunda-feira de novo e você não pode aproveitar nada no fim de semana. (JUVENAL, 2016).

A simples existência de produções agrícolas familiares já explicita pontos de resistências da cultura rural e a caracterização deste espaço enquanto tal (Silva, 2001). Portanto, a permanência do rural é nítida, apesar dos rebatimentos que as recentes transformações podem fomentar a médio e longo prazos, por exemplo, sobre os quais a empresária da UN1ONE teceu comentários quando questionada sobre a possibilidade de incentivar os produtores locais a implantarem um sistema hidropônico em suas próprias hortas:

Aqui na região não penso, porque o pessoal é muito tradicional. Eles não trocam o certo pelo duvidoso. São mais antigos, né? Não adianta. E, além disso, outra coisa que está acontecendo, não somente na nossa região, mas eu também trabalho com o pessoal da EMATER e nós estávamos fazendo curso fora, juntamente com o SEBRAE, há projeções indicando que daqui a dez anos os produtores hoje ativos não vão estar mais, porque já estarão com mais de 70 anos e seus filhos e netos não estão seguindo a tradição da família. Por exemplo, na nossa região (Vila Almeida) eram trinta famílias de produtores, e destas somente duas famílias ficaram nas hortas. $O$ resto todo mundo foi embora, formaram, foram embora pra fora, não quiseram seguir a profissão. Aquela região onde se tem o apoio das prefeituras e do governo algumas pessoas ainda se mantêm no campo porque eles ajudam a investir, aí você compra maquinário, compra tudo, não é só braçalmente. Mas os pequenos produtores são braçais, porque um trator é para hortas grandes, não cabe em hortas pequenas como as da Vila Almeida. Então a nossa região daqui a dez anos, é triste dizer isto, mas a expectativa é, se tiver, somente duas ou três hortas. Se você observar dez anos atrás, você vê que já teve uma mudança de 70 por cento. E agora dez anos pra frente, vai inteirar os 100 por cento de não existir mais. E não é só nossa região. A entrevista que eu acompanhei pelo Globo Rural Rio Grande do Sul, Santa Catarina, região de grandes produtores com tradição de pai, avô, tio... não estão conseguindo mais manter tanto a tradição. Hoje existem aquelas pessoas que financeiramente conseguem agregar maquinários, profissionais, porque em alguns casos, uma pessoa para trabalhar numa máquina tem que ser formada em alguma coisa da parte de agronomia né, então é triste falar isso. (MARIA, 2016). 
Tanto a unidade empresarial quanto os produtores mais tradicionais possuem suporte tecnológico e apoio pedagógico da EMATER-MG. Um representante da EMATER-MG que nos concedeu entrevista, Fernandes, é funcionário de carreira do órgão e desde 1997 atua na região da Vila Almeida.

A diferença entre a unidade de processamento mínimo e a produção "in natura" é que a primeira lida com a higienização, limpeza e embalagem dos produtos agrícolas. (FERNANDES, 2016).

Ele prossegue falando a respeito do início das atividades da UN1ONE:

\begin{abstract}
No início, os produtores locais venderiam para a UN1ONE o que fosse a sobra, o resto, aquilo que não fosse vendido para o mercado. Mas a eficiência econômica do processamento mínimo é rendimento. Quanto melhor a qualidade do produto, maior o rendimento, e um produto que não fosse bom para o mercado jamais serviria para ela. Então ela parou de adquirir produto na região, porque os produtos melhores os produtores locais queriam mandar para a feira, para 0 mercado. No minimamente processado, por exemplo, você manda lá uma caixa de alface com 15 quilos, se for de boa qualidade vai render $60 \%$ do material porque o restante é descarte mesmo, é o talo e tal. Se a alface não for de boa qualidade, que não dê rendimento bom, ela vai render $40 \%$. Esses percentuais não influenciam na qualidade final do produto, mas influenciam no percentual de material utilizável, e isso tem uma influência no custo final dela muito grande, brutal. Aí a conta não fecha, o negócio é inviável. Conclusão: ela parou de pegar produto da Vila. (FERNANDES, 2016).
\end{abstract}

O quadro conflituoso exposto, que resultou no rompimento da comercialização de produtos entre UN1ONE e produtores locais, é reflexo de normativas e conceitos onde as mercadorias e seu sistema de implantação tomam para si o cotidiano da Vila, apropriam-se dele e moldam-no de forma integrada à diretriz de capitalização hegemônica normativa das relações sociais. $\mathrm{O}$ modo de vida tendencialmente é instruído em direção a uma padronização através dos sinais e signos cotidianos que fundamentam a logística daquele espaço, em um panorama onde, por mais singulares que sejam as ruralidades, estejam sempre sendo pressionadas pelos processos urbanos condicionantes da formação socioespacial. Fernandes ponderou ainda algumas situações que considera importantes a respeito da proximidade da Vila Almeida com o centro da cidade de Juiz de Fora e possível adensamento urbano:

Lá tem essa característica, né? É considerado um bairro rural, mas lá tem esse misto de pessoas com características, vidas urbanas, trabalham na cidade e moram lá, e tem pessoas que moram lá, vivem lá e trabalham na atividade rural. A urbanização está ali pressionando a agricultura. Na maioria desses cinturões verdes a tendência é que a valorização dos terrenos vá expulsando a agricultura, que é o medo dos produtores lá hoje. (FERNANDES, 2016). 
Em relação à hipótese de adensamento populacional, Augusto, produtor rural e esposo da também produtora Gisele (figura 6), comparando a conjuntura territorial da Vila Almeida com outro bairro do munícipio, chamado Grama (PREFEITURA DE JUIZ DE FORA, 2000), afirma:

Se começarem a construir, nós vamos ter que acabar com as hortas. A venda de lotes, supondo, eu vendo, o outro lá vende, o outro vende, aí vira um bairro. No bairro Grama aconteceu isto. Fez hospital, fez tudo lá, as hortas quase tudo acabaram. A cidade aumentou, né... (AUGUSTO, 2016).

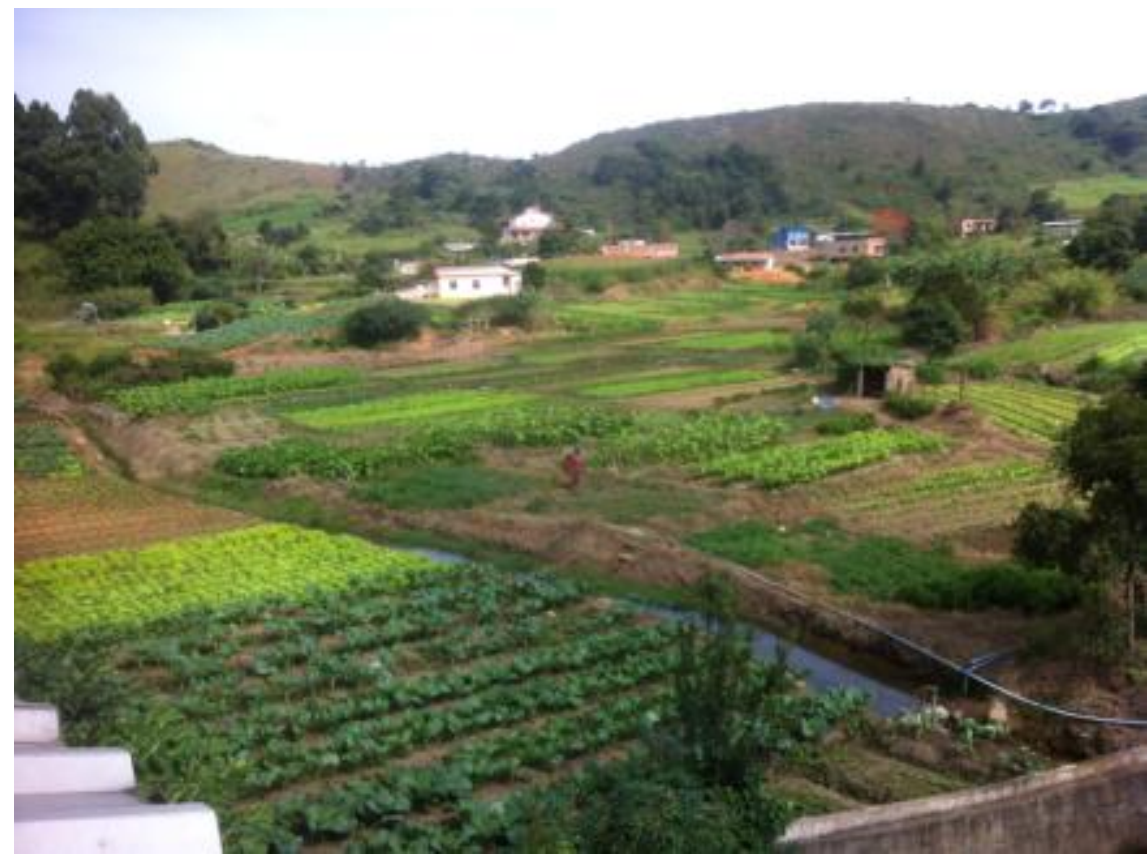

Figura 6. Dentre as hortas acima, aquelas onde os produtores rurais Gisele e Augusto cultivam, 2016.

Fonte: acervo pessoal do autor

Além disso, considerando a construção de urbano em disputa e o avanço da cidade sobre este espaço, os moradores temem a entrada de pessoas que façam surgir nesta comunidade rural, segundo eles, problemas típicos das cidades, por exemplo, a violência, a fome e as desigualdades sociais, gerando uma sensação de insegurança social. De maneira geral, os que na Vila residem:

[...] tem seu cotidiano alterado pelas inovações que chegam e a ele são apresentadas, o que o coloca em situação de difícil definição: ao mesmo tempo que deseja mais inovações (algumas nem deseja...) vê-se, cada vez mais integrado a redes de poder nas quais pouco pode exercer sua autarquia (se for pequeno proprietário) ou pouco pode resistir ao sentido geral da mercantilização [...]. (RUA, 2011, p.43/44). 
Não há como descolar do cotidiano dos indivíduos advindos do centro da cidade o modo de apropriarem-se do espaço e de se reproduzirem, o qual já concebiam corriqueiramente nos centros das cidades.

\section{CONSIDERAÇÕES FINAIS}

O debate acerca da temática rural/urbano, neste trabalho específico, a priori parte da análise da existência e funcionamento da empresa agrícola UN1ONE no bairro da Vila Almeida, em Juiz de Fora, Minas Gerais. Entretanto, no decorrer da pesquisa, as evidências de um espaço rural transformado se desdobram e denotam outros processos de articulação que explicitam o vínculo entre características rurais e urbanas. No espaço híbrido da Vila, independentemente de que modo ou através de quais meios, pode-se concluir que ruralidades e urbanidades coabitam nas relações sociais daqueles indivíduos, sendo que estes sujeitos em sua reprodução social estão condicionados por seus espaços de vivência e, ao produzirem neles, também os condicionam e os transformam fazendo surgir novas espacialidades/territorialidades, fenômenos estes deflagrados contemporaneamente na conjuntura social da Vila Almeida.

A intensidade das transformações que ali ocorrem é cada vez maior, à medida que o caldo cultural do ambiente é muito rico e diverso, e importante é ressaltar, descontruindo o conceito de homogeneização inevitável e do mito histórico de prevalência da cidade sobre o campo, do urbano sobre o rural e da indústria sobre a agricultura, a amplitude com que a rede local fomenta muitas ruralidades na construção do urbano em formação. Ainda hoje, são bastante singulares as diretrizes agrícolas daquele espaço, e elas fundamentam uma resistência a partir de suas peculiaridades e promovem uma conjuntura de organização do território em que a produção rural preponderantemente ainda é pensada como o principal vetor dinâmico da Vila, porque a força das representações dos sujeitos que ali residem parte deles próprios, em sua ação social. Pode-se concluir que, da maneira como se reproduzem no espaço, eles criam sua consciência, a partir das próprias determinantes e de elementos que constroem, e se estruturam em prol da manutenção de muitas tradições agrícolas, agora perpassadas por novas determinantes, pois costumes e hábitos externos lhes surjam como novos apontamentos. 
Dentre todos os vetores externos de urbanidades que deflagram novas territorialidades, temos a empresa UN1ONE que, através de meios e processos produtivos vigentes no seu modo de operação, agrega novos valores, técnicas e hábitos à cultura de hortaliças e fomenta certo dinamismo que tende a urbanizar (padronizar certa racionalidade e logística cotidiana) toda a conjuntura socioterritorial da Vila, causando rebatimentos nas relações diárias dos indivíduos. A territorialidade cada vez mais ampla de atuação da empresa nos mercados centrais da cidade de Juiz de Fora contribui para redefinir hierarquias socioespaciais, pois a UN1ONE atualmente constrói seu nicho de mercado para além de feiras livres e pequenos mercados, tradicionais locais de comercialização de hortaliças. Hospitais, escolas, buffets, restaurantes e outros compradores encontram no modo de distribuição da empresa o caminho mais vantajoso para aquisição dos produtos que demandam, não tendo a necessidade de ir até o local de compra, mas recebendo suas entregas. Além disso, as hortaliças processadas pela UN1ONE chegam empacotadas ao seu destino e em quantidades previamente calculadas. Estas características são vantagens competitivas criadas pela própria empresa, que se ordena no mercado, pautada por conhecimentos e saberes advindos do sistema mercadológico citadino. Portanto, no arcabouço dessas transformações há conflitos e tensões, motivadas pelo fato de variados outros produtores agrícolas manterem suas tradições rurais e resistências diante da necessidade de distribuição de suas mercadorias em um mercado urbano competitivo. É nítido então que territorialidades, a partir das relações rural/urbano, são relacionadas aos movimentos de constituição do exercício de poder e da hegemonia dos atores que estruturam suas identidades sociais, nesta conjuntura espacial enquanto “espaço/processo" (RUA, 2005), ou seja, o espaço socialmente construído. Dado as racionalidades próprias das forças sociais, a homogeneização do contexto rural sob égide das diretrizes citadinas não é algo inevitável.

Em se tratando daquela essência cotidiana híbrida, ela é síntese de um fenômeno mais abrangente quando em sua totalidade, que não se constitui sem as tensões que permeiam toda a cadeia de trocas culturais e permuta de informações, quando estas se dão em processos de vivência na rede de intercâmbio de hábitos e culturas. É crucial, portanto, entender esta essência enquanto uma disputa de territorialidades que variam diariamente devido ao poder de influência dos atores sociais, sendo que essa referência e predominância se desenrolam na rede de fluxos, ou seja, nos grupos e espaços de 
vivências coletivas, impondo uma logística e racionalidade no espaço de reprodução social. É entendimento claro que não há dicotomia entre os distintos espaços rural e urbano, todavia, há, sim, uma complementariedade entre cidade e campo em variadas determinações que se formam na práxis.

\section{REFERÊNCIAS}

ABRAMOVAY, R. Funções e medidas da ruralidade no desenvolvimento contemporâneo. Distribuição espacial da população brasileira: concentração versus desconcentração. Diretoria de Estudos Sociais do IPEA. Rio de Janeiro, 2000.

ARAUJO, J. A. Sobre a Cidade e o Urbano em Henri Lefébvre. GEOUSP - Espaço e Tempo. São Paulo. N31. 2012.

CARNEIRO, M. J. Ruralidade: novas identidades em construção. Estudos Sociedade e Agricultura, 11, outubro 1998: 5375.

EMATER. Programa de Desenvolvimento Sustentável da Comunidade Vila Almeida. Empresa de Assistência Técnica e Extensão Rural do Estado de Minas Gerais. Diagnóstico Participativo, 2011.

ENDLICH, A. M. Perspectivas sobre o urbano e o rural. In: SPOSITO, M. E. B. WHITACKER, A. M. (organizadores) Cidade e campo: relações e contradições entre urbano e rural. 3. ed. - São Paulo: Outras Expressões, 2013.

LABHIDRO. Hidroponia. www.labhidro.cca.ufsc.br | C Copyright 2012 Universidade Federal de Santa Catarina - Centro de Ciências Agrárias Departamento de Engenharia Rural - Laboratório de Hidroponia - LabHidro. Disponível em: http://www.labhidro.cca.ufsc.br/hidroponia-2. Acesso em: 7 de junho 2016.

LEFÉBVRE, H. De lo rural a lo urbano. Antología preparada por Mario Gaviria. edición original francesa publicada por Éditions Anthropos, con el titulo "Du rural aI'urbain”. Editions Anthropos. Paris 1970. Traducción de Javier González Pueyo. Barcelona, 1978.

LIMA, E. N. Novas ruralidades, novas identidades. Onde? In: MOREIRA R. R. Identidades sociais: ruralidades no Brasil contemporâneo. (org.); Maria José Carneiro... [et al.]. - Rio de Janeiro: DP\&A, 2005.

MARAFON, G. J. Territorialidades, ruralidades e as relações campo-cidade. CAMPO-TERRITÓRIO: revista de geografia agrária. Edição especial do XXI ENGA-2012, p. 1-13, jun., 2014.

NETTO, J. P. Formação profissional: trajetórias e desafios. Cadernos ABESS. São Paulo, Cortez, ed. esp., n. 7, novembro de 1997. Disponível em: http://www.pcb.org.br/portal/docs/int-metodo-teoria-social.pdf. Acesso em: 07/09/2015 PREFEITURA DE JUIZ DE FORA, Juiz de Fora Sempre: Plano Diretor de Desenvolvimento Urbano de Juiz de Fora FUNALFA edições, 2000.

RUA, J. Abordagens teórico-metodológicas em geografia agrária / organizadores: Glaucio José Marafon, João Rua, Miguel Angelo Ribeiro. - Rio de Janeiro: EdUERJ, 2007.

A complexa simultaneidade da integração e distinção entre o urbano e o rural: retomando um debate no espaço de metropolização no estado do Rio de Janeiro. GEOPUC - Revista do Departamento de Geografia da PUC-Rio. Ano 4 número 7 - segundo semestre de 2011 
Urbanidades no rural: o devir de novas territorialidades. CAMPO-TERRITÓRIO: Revista de Geografia Agrária, Uberlândia, volume 1, número 1, p. 82-106, fev. 2006.

SILVA, J. B. Discutindo o rural e o urbano. Revista da ANGEPE, v. 7, n. 8, p. 3-11. Ago./dez. 2011

SOBARZO, O. O urbano e o rural em Henri Lefébvre. In: SPOSITO, M. E. B. WHITACKER, A. M. (organizadores) Cidade e campo: relações e contradições entre urbano e rural. 3. ed. - São Paulo: Outras Expressões, 2013. 